\title{
Effect of Methylprednisolone on Experimental Brain Edema in Rats - Own Experience Reviewed
}

\author{
Petr KOZLER ${ }^{1}$, Dana MAREŠOVÁ ${ }^{1}$, Jaroslav POKORNÝ ${ }^{1}$ \\ ${ }^{1}$ Institute of Physiology, Charles University, First Faculty of Medicine, Prague, Czech Republic
}

Received April 15, 2021

Accepted October 11, 2021

\begin{abstract}
Summary
Brain edema - a frequently fatal pathological state in which brain volume increases resulting in intracranial pressure elevation can result from almost any insult to the brain, including traumatic brain injury. For many years, the objective of experimental studies was to find a method to prevent the development of brain edema at the onset. From this perspective, the use of methylprednisolone (MP) appears promising. High molecular MP ( $M W>50 \mathrm{kDa}$ ) can be incorporated into the brain - in the conditions of the experimental model - either by osmotic bloodbrain barrier disruption (BBBd) or during the induction of cellular edema by water intoxication (WI) - a condition that increases the BBB permeability. The time window for administration of the MP should be at the earliest stages of edema. The neuroprotective effect of MP on the permeability of cytoplasmatic membranes of neuronal populations was proved. MP was administrated in three alternative ways: intraperitoneally during the induction of cytotoxic edema or immediately after finishing cytotoxic edema induction in a dose of $100 \mathrm{mg} / \mathrm{kg}$ b.w.; into the internal carotid artery within $2 \mathrm{~h}$ after finishing cytotoxic edema induction in a dose of $50 \mathrm{mg} / \mathrm{kg}$ b.w.; into internal carotid artery $10 \mathrm{~min}$ after edema induction by BBBd in a dose of $50 \mathrm{mg} / \mathrm{kg} \mathrm{b.w}$.
\end{abstract}

\section{Key words}

Cytotoxic edema • Vasogenic edema • Water intoxication • Blood brain barrier disruption • Methylprednisolone

\section{Corresponding author}

J. Pokorný, Institute of Physiology, First Faculty of Medicine, Charles University, Albertov 5, Praha 2, 128 00, Czech Republic. E-mail: jaroslav.pokorny@lf1.cuni.cz

\section{Introduction}

Brain edema is "an abnormal accumulation of fluid associated with volume enlargement of the brain". This is how Klatzo described brain edema in 1967. Based on experimental models of cold lesions and the use of neurotoxin, he defined two pathogenetically different brain edemas - vasogenic and cytotoxic (Klatzo 1967). The current classification of cerebral edema is based on experimental studies from the end of the $20^{\text {th }}$ century. Edema is understood as a disorder of homeostasis of the internal environment of the brain and the classification of edema is based on the morphological profile of fluid distribution - intracellular (cytotoxic) or extracellular (vasogenic) type. Studies also show that any brain edema is essentially "vasogenic" because the volume enlargement of the brain occurs only after fluid enters the brain across the blood-brain barrier (BBB), but its permeability can be increased primarily by a "cytotoxic" insult (Betz et al. 1989, Bartzó et al. 1997, Kimelberg 1995, Kempski 2001). It was not until the $21^{\text {st }}$ century that the important role of brain aquaporins in the genesis and further development of brain edema was clarified. (Venero et al. 2001, Marmarou 2003). From a purely pathophysiological point of view, interstitial and osmotic edema are still classified. In the current conception, interstitial edema (CSF leakage into the brain during hydrocephalus) is an extracellular type and osmotic edema (a disorder of osmoregulation at the cellular level - a form of cytotoxic insult) is an intracellular type (Stokum et al. 2016).

In clinical practice, brain edema is a serious condition. As follows from its definition, increased volume leads to a life-threatening intracranial 
hypertension in a closed, rigid skull. Brain edema is a detrimental phenomenon in many pathological conditions for which causal treatment is not yet known, such as traumatic brain injury or cerebral ischemia - to name but a few, but the most serious. It is therefore not surprising that the study of the pathophysiology of cerebral edema and the search for neuroprotective drugs receives long-term and focused attention. The current knowledge on this issue is summarized in some excellent review articles (Stokum et al. 2016, Stokum et al. 2020, Kochanek et al. 2015, Jha et al. 2019).

Our research into brain edema and neuroprotection has led through experimental models of cytotoxic (osmotic) and vasogenic brain edema and the use of MP in the prevention of the onset and development of brain edema. Although we have gradually published the individual results (Kozler and Pokorný 2004, Kozler and Pokorný 2012, Kozler et al. 2017, Kozler et al. 2020), we now consider it useful to emphasize the basic principles of the experimental models used to test the effect of methylprednisolone (MP) in the form of a review article. Our experimental models are based on the contemporary concept of brain edema: two main types of brain edema are classified - vasogenic edema, and cytotoxic edema. Vasogenic edema is characterized by extravasation and extracellular accumulation of fluid into the cerebral parenchyma caused by disruption of the blood-brain barrier (BBB). In contrast, cytotoxic edema is characterized by intracellular accumulation of fluid and $\mathrm{Na}^{+}$resulting in cell swelling. Although cytotoxic edema is characterized by intracellular accumulation of fluid, it makes BBB more permeable with water accumulation in extracellular space - the main feature of vasogenic edema (Ayata and Ropper 2002, Liang et al. 2007, Marmarou 2007, Michinaga and Koyama 2015, Stokum et al. 2016, Sorby-Adams et al. 2017).

All experiments were approved by the Ethical Committee of the First Faculty of Medicine (Charles University in Prague) and were in agreement with the Guidelines of the Animal Protection Law of the Czech Republic and Guidelines for the treatment of laboratory animals EU Guidelines 86/609/EEC. For experiments, male rats of the Wistar strain weighing 400 to $410 \mathrm{~g}$ of our own breed were used.

\section{Experimental models of the brain edema induction}

To induce the cytotoxic (osmotic - intracellular) edema, we use the water intoxication (WI) model. This model best reflects simulation of hyponatremia because it induces a relative decrease of extracellular $\mathrm{Na}^{+}$concentration. Generally, the water intoxication model is produced by the intraperitoneal loading of a large volume of distilled water corresponding to $10-40 \%$ of the body weight of experimental animals. This excessive load of water induces an increase of water content in the tissues of the central nervous system and an intracellular influx of water which results in brain swelling (Manley et al. 2000, Kozler and Pokorný 2003, Yang et al. 2008, Kozler et al. 2013, Kozler and Pokorný 2014, Kozler et al. 2018). In details the modified method of WI is based on intraperitoneal (i.p.) administration of distilled water (DW) in the total amount corresponding to $20 \%$ of body weight in three consecutive doses over $24 \mathrm{~h}$ with a simultaneous administration of desmopressin. Each sub-dose represented one-third of the total dose of $0.032 \mathrm{mg} / \mathrm{kg}$ of desmopressin (1-desamino-8-D-arginine vasopressin) (OCTOSTIM $\AA$, Ferring). Desmopressin is an antidiuretic hormone, which potentiates the effect of hyperhydration by inducing hyponatremia (Manley et al. 2000, Silver et al. 1999, www.rxmed.com/b.main/b2.pharmaceutical/OCTOSTIM. html).

Demonstration of the presence of brain edema after WI was provided by models studying the brain water content and CT (computed tomography) density. Results proved that the water content was significantly increased after WI. We used three different volumes of distilled water, corresponding to $20 \%, 30 \%$ or $40 \%$ of the animal's body weight. We found that the larger was the volume of distilled water the higher water content in the brain was achieved. (Kozler et al. 2013, Kozler et al. 2018). We studied the CT density in group of intact rats and in the group of rats after WI (Kozler and Pokorný 2014, Kozler et al. 2018). CT scans with a pixel size $0.125 \mathrm{~mm}$ were done in regions of interest (ROI) corresponding to the area of coronary sections in three different positions, with bregma being the reference mark (bregma $+2.43 \mathrm{~mm}$, bregma $+2.92 \mathrm{~mm}$ and bregma + $12.73 \mathrm{~mm}$ ) in both groups of animals. The CT density of the brain tissue in each scan was stated as mean value of Hounsfield Units (MV HU). Under physiological conditions the CT density of the human brain is in the range of 29 to $38 \mathrm{HU}$ (Kucinski et al. 2002, Mangel et al. 2002). If, under pathological conditions, the density decreases at least by $12 \mathrm{HU}$, the radiological criterion for the presence of brain edema is fulfilled (Clasen et al. 
1981, Torack 1982). The overall average density in the group after WI, was $32.48 \mathrm{MV}$ HU, a decrease high enough to conclude that rats after WI had brain edema which according to its way of origin should be of intracellular type.

To model a vasogenic (extracellular) edema, we used the method of BBB disruption by intracarotid injection of hyperosmolar solution (Kozler and Pokorný 2003, Kozler et al. 2014, Kozler et al. 2015). Administration of a hyperosmolar solution into the internal carotid artery (ICA) causes shrinkage of endothelial cells in capillaries, which leads to the expansion of tight junctions to an average of 20 times their normal diameter. Owing to the distension of the tight junctions, BBB becomes permeable to highmolecular compounds, which should be followed by influx of water in the direction of osmotic gradient (Rapoport 2000). Our method of the microsurgical exposure of ICA and Mannitol injection is described in details here: animals are put into the state of general anesthesia using intraperitoneal application of thiopental in the dose of $4 \mathrm{mg} / 100 \mathrm{~g}$ of inhalation anesthesia by isoflurane (Florante $\AA$, AbbVie Ltd.) and allowed to ventilate spontaneously throughout the procedure. Starting from a skin incision along the midline between the upper end of the sternum and the mandible, the common carotid artery (CCA) was exposed with a standard microsurgical technique and, before its bifurcation, also the proximal portions of the external carotid artery (ECA), which was ligated close beyond the bifurcation. An intraluminal catheter was introduced into the ICA trunk through the arteriotomy for injection of Mannitol $20 \%$ (200 g in $1000 \mathrm{ml}$ of water for injection, $1098 \mathrm{mosmol} / \mathrm{l}$ ) in a dose of $5 \mathrm{ml} / \mathrm{kg}$ at a rate of $0.12 \mathrm{ml} / \mathrm{sec}$. With the application over and the catheter removed, the ICA was ligated. The surgery concluded with a single-layer suture (Kozler and Pokorný 2003, Saris et al. 1988, Kroll and Neuwelt 1998, Rapoport 2000).

The presence of extracellular edema after BBBd was confirmed by distribution of intravital markers and by increased brain water content. BBB permeability can be tested by different methods. The most widely used one in experimental models is an intravenous administration of intravital markers of molecular weight greater than 180 Da preclude passage across an intact barrier. In terms of molecular size, these markers represent a broad spectrum of markers, in which Evans blue is one of the largest - in blood circulation it becomes bound to the albumin fraction of proteins to give rise to a highmolecular complex - EBA $68500 \mathrm{Da}$ (Broman and Olsson 1949, Kroll and Neuwelt 1998, Lafuente et al. 1990, Wolman et al. 1981). In our experimental model we proved the distribution of high-molecular EBA tracer injected into ICA after osmotic BBBd in extracellular brain compartment by way of fluorescence microscopy (Kozler and Pokorný 2003) which means that owing to the distension of the tight junctions, BBB becomes permeable to high-molecular substances, which should be followed by water in the direction of osmotic gradient (Rapoport 2000). After the osmotic BBBd the water content significantly increased (Kozler et al. 2013). Not all authors studying the relationship between osmotic $\mathrm{BBBd}$ and rise of water content in the brain came to the same conclusion. Rapoport et al. (1980) described transient increase of water content (1.0-1.5\%) after the osmotic BBBd; Kaya et al. (2004) found significantly higher water content in rats with osmotically opened BBB. By contrast, Marchi et al. (2009) stressed that the osmotic BBBd was followed by protein extravasation and the total water content of the brain was not increased. However, all of them admitted, that as a result of the accumulation of osmotically active substances, including proteins, in the extracellular space some exchange of water between the cellular and extracellular compartment could develop. Similar findings published also Chi et al. (2000).

\section{Experimental models for testing the neuroprotective effect of methylprednisolone}

Methylprednisolone (MP) in the damaged central nervous system can induce its positive effect by several mechanisms depicted by Park (1998). The primary neuroprotective effect of MP is attributed to its antioxidative ability which protects membrane lipids from peroxidation and against all subsequent adverse effects like changes in membrane fluidity or changes in the activity of membrane proteins (ion channels, transporters, enzymes). The reactive oxygen species affect also other cellular systems (mitochondria, intracellular enzymes and co-factors, systems of transcription and translation), thus altering various parameters of cell activity or inducing the cell death by apoptosis. Hence, the antioxidative ability of MP could interfere with the pathogenic process in nerve cells at different levels. Being a steroid, MP has a lipophilic nature and is only weakly soluble in water. For being 
distributed in the body fluids it has to be in the form of ester methylprednisolone sodium succinate (MPSS). MPSS is not stable and due to activity of hepatic esterases, MP is released and subsequently bound to plasma proteins in the ratio of 40 to $60 \%$. Contrary to the free liposoluble MP, the high-molecular complexes cannot cross the blood-brain barrier. Only about one half of the total MPSS administered intravenously or intraperitoneally can cross the BBB (Hall 1992). MP is metabolized in the liver with a mean elimination half-life in the range from 1.8 to $5.2 \mathrm{~h}$ (www.pfizer.cz/sites/pfizer.cz/files/g10034396/f/201608/ Solu-Medrol_40mg_PIL.pdf).

We studied the neuroptective effect of Methylprednisolone (Solu-Medrol ${ }^{\circledR}, \quad$ Pfizer) in experiments on rats in two neurohistological and two preclinical studies. Before testing the MP effect, we needed to know the answers to three questions - how to apply MP (1), when to apply MP (2), what should be the dose of MP (3)? (1) The effect of MP in preventing the onset and development of brain edema can only be used when the BBB permeability is increased. High molecular weight MP bound to the albumin (MW>50 kDa) can be incorporated into the brain either by osmotic BBB disruption or during the induction of cellular edema by WI - condition that increases the permeability of BBB. (2) The so-called therapeutic window, in which MP in the brain is effective, depends on its metabolism in the body. MP is metabolized in the liver with a mean elimination half-life in the range from 1.8 to $5.2 \mathrm{~h}$. MP should be given very early (within a few hours after the onset of edema). (3) The neuroprotective effect of MP has since been observed in experiments at doses ranging from 30 to $105 \mathrm{mg} / \mathrm{kg}$ body weight.

In the first neurohistological study (Kozler and Pokorný 2004) we tested the effect of MP on the permeability of cytoplasmatic membranes of neuronal populations in cortex a hippocampus in groups of animals with induced both cytotoxic (WI) and vasogenic edema (BBBd). All animals underwent the induction of the cytotoxic edema by means of WI prior to next step which was BBBd with mannitol. $30 \mathrm{~s}$ after mannitol infusion, MP (dose $54 \mathrm{mg} / \mathrm{kg}$ ) and then $2 \%$ Evans blue (dose $2 \mathrm{ml} / \mathrm{kg}$ ) at a rate of $0.45 \mathrm{ml} / \mathrm{min}$ were injected into the same catheter placed in ICA. After $30 \mathrm{~min}$, fixation was performed by transcardial perfusion with $4 \%$ solution of paraformaldehyde and coronary sections $40 \mu \mathrm{m}$ thick were prepared for fluorescence microscopy analysis. We studied distribution of Evans Blue (EB) in both the intracellular and extracellular compartments of cortex and hippocampus (CA1, CA3 and GD) in both hemispheres by determining the intracellular distribution index value. The intracellular distribution index (IDI) is a precisely defined quantity from 0 to 2 . With IDI=1, the distribution of EB between the intracellular and extracellular compartments is in equilibrium. IDI in excess of 1 indicates more EB in the cells than in the extracellular compartment. When IDI is less than 1, most of the EB remains outside cells. The results showed that if only EB was applied to the ICA, the IDI values were higher than one, indicating a predominant intracellular distribution of the marker. On the other hand, when MP was applied before EB, the IDI values were less than one, indicating a predominant extracellular distribution of the marker. Figure 1 shows the mean IDI values obtained from the cortex and hippocampal areas CA1, CA3 and GD of both hemispheres in three rats in each group. The mean IDI of 1.375 in the EB group dropped to 0.6 in the MP $+\mathrm{EB}$ group. This decrease is statistically significant according to a two-tailed Student $t$-test.

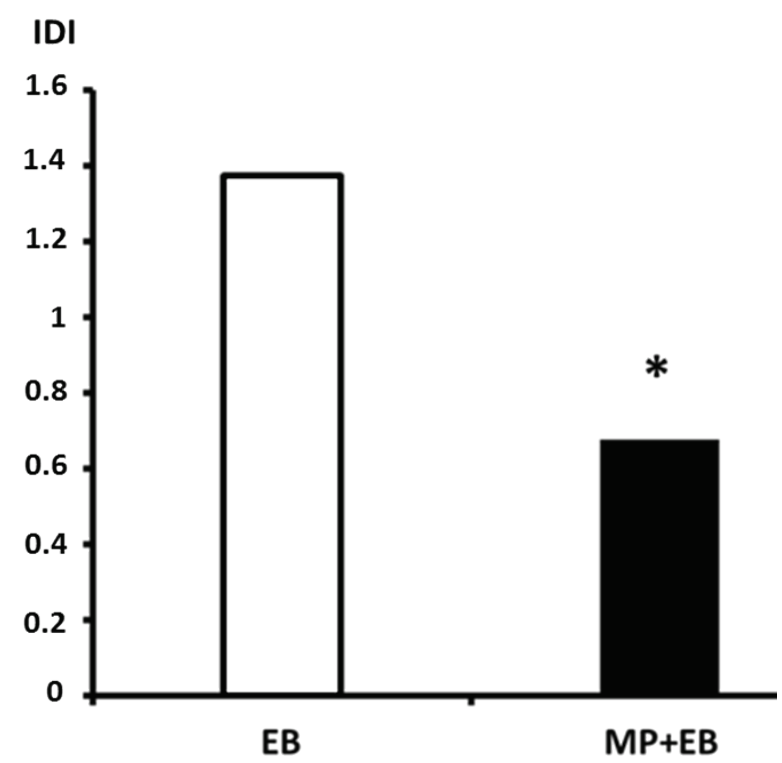

Fig. 1. Intracellular distribution index (IDI) values. Columns with mean IDI values, white column: EB group, black column: $\mathrm{MP}+\mathrm{EB}$ group; $\left(^{*}\right)$ denotes statistically significant difference $(p<0.05)$.

In EB group, the increased permeability reflects loss of membrane integrity. The primary role in this phenomenon is played by inhibition of the physiological function of membrane $\mathrm{Na}^{+} / \mathrm{K}^{+}$ATPase as a result of disordered cellular-level osmoregulation due to water intoxication. In MP + EB group the results show 
morphological evidence of cell membrane integrity restored under the effect of MP. MP uses its antioxidant properties, thus preventing irreversible peroxidation of lipids and creating conditions for maintaining cell membrane functions. Therefore, significantly less EB infiltrates the cells.

In the second neurohistological study (Kozler and Pokorný 2011) we studied MP for its effects on axonal impairment caused by induced vasogenic edema. It was shown in our previous paper, that BBBd by mannitol induced brain edema brings about signs of myelin degradation which evidently progress, as evident from the higher intensity of myelin changes in the longer time intervals from the edema induction - the shortest interval was one hour and the longest one week (Kozler et al. 2010). In a neurohistological study testing MP, we focused on the early onset of edema and the development of morphological changes. All animals underwent BBBd and MP administration. In one group (MP-PER), MP was injected intraperitoneally at a dose of $100 \mathrm{mg} / \mathrm{kg}$ body weight after the end of mannitol application to the ICA. In another group (MP-ICA), MP was injected at a dose of $100 \mathrm{mg} / \mathrm{kg}$ body weight into the ICA $10 \mathrm{~min}$ after the end of mannitol administration. Perfusion fixation followed in $30 \mathrm{~min}$ in all groups. Coronary sections $30 \mu \mathrm{m}$ thick were prepared (Black Gold II method of staining) for microscopy analysis of hippocampal areas CA1, CA3, GD i both hemispheres. The neurohistological picture of the structural integrity of the axons was assessed with the aid of the following grades of myelin degradation: $1=$ no change, $2=$ sporadic oedematous distensions, solitary axonal swelling, $3=$ multiple vesicles, varicosities, edematous axons and helical course of axons, $4=$ myelin fragmentation. Figure 2 shows the mean grade of myelin involvement obtained from 10 sections of each hippocampal area from both hemispheres in five rats in each group. The mean grade of myelin involvement of 3.5 in the BBBd group dropped to 2.6 in the MP-ICA group and to 2.1 in the MP-PER group. This decrease is statistically significant according to a $t$-test and one-way analysis of variance (ANOVA) followed by Dunnett post hoc analysis.

Results revealed an evident neuroprotective effect of MP. Myelin degradation was less extensive after the MP administration either it was given into the carotid artery or to the peritoneum. This phenomenon is based on the recognition that any morphological change in myelin integrity must be preceded by a phase of brain edema (Onaya 2002). The intensity of brain edema required to initiate morphological changes in myelin was evidently smaller with early administration of MP.

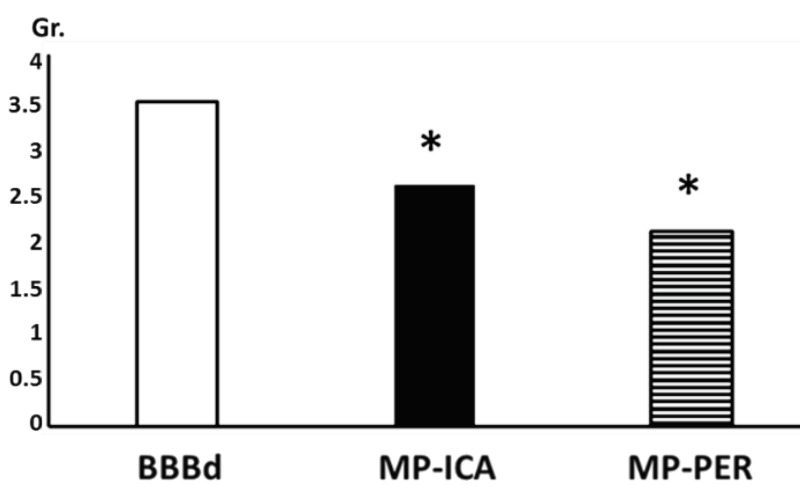

Fig. 2. Myelin degradation. Columns represent the mean grade (Gr.) of myelin degradation (vertical scale); white column: BBBd group - edema induction, black column: MP-ICA group - MP was injected into ICA, striped column: MP-PER group - MP was injected intraperitoneally; $(*)$ denotes statistically significant difference $(p<0.05)$ from BBBd group.

In the first preclinical study (Kozler et al. 2017), we tested the effect of MP on the intracranial pressure (ICP) values in brain edema. Normal ICP mean values of $4.62 \pm 1.24 \mathrm{~mm} \mathrm{Hg}$ were obtained by continuous ICP monitoring in eight healthy rats. A cytotoxic edema was induced by WI. MP $(100 \mathrm{mg} / \mathrm{kg})$ was administered intraperitoneally before the start of edema induction (group MP $+\mathrm{WI}$ ), during induction (group WIMP) and after induction (group WI + MP). When MP was administered during or at the end of edema induction, it penetrated into the brain due to the increased permeability of BBB. It could therefore affect the permeability of the cytoplasmic membrane, block the intracellular water accumulation, and prevent development of an edema already at the initial stage. Figure 3 shows the mean ICP values obtained from a 60 -minute continuous monitoring of eight rats in each group. The mean ICP values of $14.25 \pm 2.12 \mathrm{~mm} \mathrm{Hg}$ in the WI group dropped to $5.52 \pm 1.32$ in the WIMP group, to $6.23 \pm 0.73$ in the WI + MP group and to $10.55 \pm 1.27$ in the MP + WI group. This decrease is statistically significant only in groups WIMP and $\mathrm{WI}+\mathrm{MP}$, while in group MP $+\mathrm{WI}$ the decrease is not statistically significant according to parametric ANOVA and nonparametric Kruskal-Wallis tests.

The mean ICP values obtained in the WIMP and WI + MP groups do not differ statistically from the mean normal ICP value in healthy animals. These results revealed normal brain volume homeostasis, with the volume and ICP corresponding to normal values of a rat 
in horizontal position. The timing of MP application during or after edema induction reduces the development of edema and therefore ICP does not increase. If the MP dose is administered before the onset of edema induction, the BBB penetration conditions for the high molecular weight substance are not met and no effect of MP is seen.

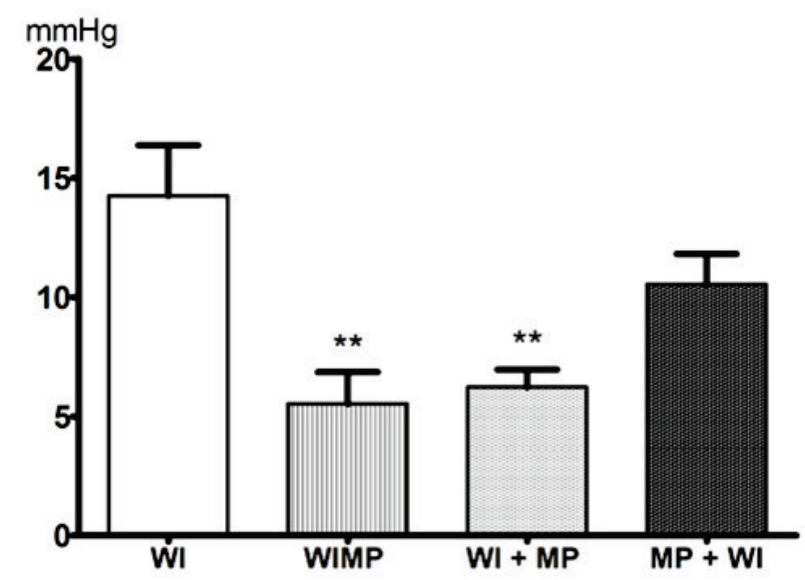

Fig. 3. Mean values of intracranial pressure (ICP). x-axis: ICP value in $\mathrm{mm} \mathrm{Hg}$, y-axis: WI - rats with induced $C E$; WIMP - MP was administered during the CE induction; WI + MP - MP was given after the completion of CE induction; $M P+W I$ - MP was administered before the CE induction. Significance $(p<0.1)$ between the group with water intoxication only and individual MP administered groups is given **.

In the second preclinical study (Kozler et al. 2020), we tested the effect of MP on brain edema by means of Magnetic Resonance Imiging (MRI). The animals were subjected to MR scanning (quantitation of apparent diffusion coefficient - ADC) before brain edema induction (group $\mathrm{CG}$ ) and one day after edema induction by WI ( $24 \mathrm{~h}$ after the last water dosage application group WI). MP was applied to other animals. In the WIMP group, MP (100 mg/kg) was applied during edema induction with each dose of water. In the WI + MP group, MP $(50 \mathrm{mg} / \mathrm{kg})$ was administered to the ICA two hours after completion of induction with the last dose of water. Diffusion coefficients were evaluated in the cortex and hippocampus in both hemispheres. Figure 4 shows the mean ADC values obtained from 8 animals in each group. The mean ADC values in healthy rats (group $\mathrm{CG}$ ) $625 \pm 27 \times 10^{-6} \mathrm{~mm}^{2} / \mathrm{s}$ increased to $684 \pm 77 \times 10^{-6} \mathrm{~mm}^{2} / \mathrm{s}$ one day after induction of brain edema (group WI) in the cortex and from $754 \pm 46 \times 10^{-6} \mathrm{~mm}^{2} / \mathrm{s}$ to $793 \pm 44 \times 10^{-6} \mathrm{~mm}^{2} / \mathrm{s}$ in the hippocampus. This increase in ADC values is statistically significant according to an unpaired two-tailed $t$-test and corresponds to the presence of vasogenic edema after WI - increased ADC values correlate with an experimental vasogenic (extracelullar) edema (Loubinoux et al. 1997). In general, a cytotoxic edema induced by an experimental model of WI occurs immediately following the osmotic insult to the brain and is characterized by the intracellular accumulation of fluid (Ayata and Ropper 2002). The word "immediately" has the greatest meaning in that statement. However, the types of edema change over time (Barzó et al. 1997, Marmarou 2003, Marmarou 2007). While cytotoxic edema is characterized by intracellular fluid accumulation, it increases BBB permeability and in $24 \mathrm{~h}$ water accumulates in the extracellular space - the main feature of vasogenic edema (Lythgoe et al. 2000, SorbyAdams et al. 2017). Mean ADC values dropped to $612 \pm 34 \times 10^{-6} \mathrm{~mm}^{2} / \mathrm{s}$ in the cortex, and to $759 \pm 50 \times 10^{-6} \mathrm{~mm}^{2} / \mathrm{s}$ in the hippocampus after intraperitoneal MP application (group WIMP). Mean ADC values dropped to $599 \pm 25 \times 10^{-6} \mathrm{~mm}^{2} / \mathrm{s}$ in the cortex, and to $730 \pm 48 \times 10^{-6} \mathrm{~mm}^{2} / \mathrm{s}$ in the hippocampus after MP application into ICA (group WI + MP). This decrease in ADC values is statistically significant according to an unpaired two-tailed $t$-test. No statistically significant differences in ADC values were found between healthy animals (group CG) and animals with applied MP (groups WIMP and WI + MP), indicating the absence of edema.

Because MP was applied $24 \mathrm{~h}$ after the induction of brain edema - at a time of increased BBB permeability - its neuroprotective effect could be utilized. Both ways of MP application - intraperitoneally or to the ICA - led to the same effect.

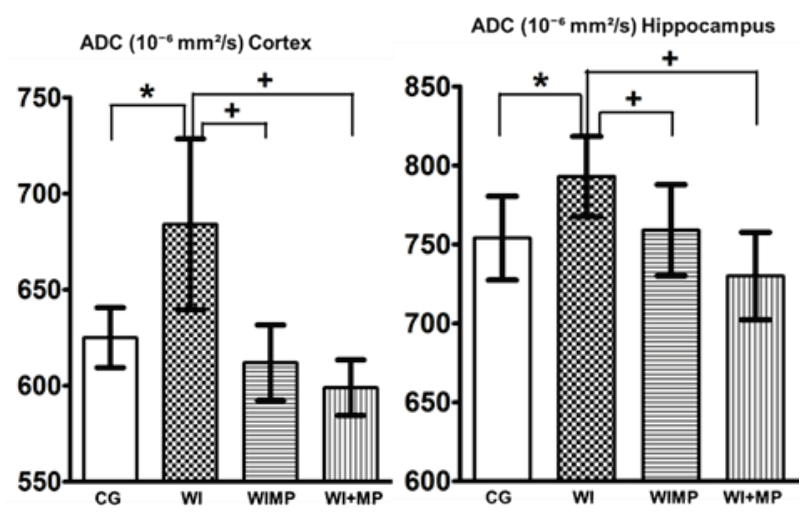

Fig. 4. Mean apparent diffusion coefficient (ADC) values in Cortex and Hippocampus. Columns with average value $\pm S D$, white columns: control group (intact animals, no WI), checkered columns: groups after edema induction by WI, horizontally striped columns: groups WIMP - edema induction by WI and MP administration intraperitoneally, vertically striped columns: groups WI + MP - edema induction by WI and MP administration into carotid artery. $\left(^{*}\right)$ denotes statistically significant difference $(p<0.05)$ from CG group, $(+)$ denotes statistically significant difference $(p<0.05)$ from WI group at the same time interval. 


\section{Discussion}

Neuroprotective drugs are a subject of unflagging interest in experimental projects and clinical trials. The results of these studies are promising, but their significance for clinical practice is still small (Stokum et al. 2016, Stokum et al. 2020, Kochanek et al. 2015, Jha et al. 2019). So far, only one drug with a proven neuroprotective effect, verified by a randomized study, is used in practice. It is methylpredenisolone (MP) in the treatment of post-traumatic spinal cord injury (Bracken et al. 1984, Bracken et al. 1990, Bracken et al. 1997). This neuroprotective effect of MP in clinical practice determined to start our testing of its effect in experimental brain edema. We have already briefly mentioned the properties of MP, now we will deal with them in more detail. The primary neuroprotective effect of methylprednisolone (MP) is put down to its antioxidative capacity for removing lipid peroxides in cell membrane. The process of antioxidation protects cell membranes against damage mediated by free radicals released by unsaturated fatty acids oxidation going on in the cells in the presence of molecular oxygen. The main neuroprotective effect of MP rests in that it prevents irreversible lipid peroxidation and a cascade of events resulting from a shortage of sources of energy. This takes the form of a change in the flow of ions on the cell membrane leading to intracellular edema and accumulation of extracellular glutamate, which is released in considerable quantities from postsynaptic membranes. Activated glutamate receptors open calcium channels and set off calcium influx into the cell. High levels of intracellular calcium cause damage to the cytoskeleton beside activating phospholipase A. That, in turn, sets off a cascade of arachidonic acid metabolites while released toxic eicosanoids (prostaglandins, leucotriens and thromboxanes) induce aggregation of thrombocytes, vasoconstriction and intravascular thrombosis. In another effect, arachidonic acid metabolites release more lipid peroxides, thus completing membrane damage (Hall 1992, Amar and Levy 1999, Faden and Salzman 1992, Hall 1993, Hall and Braughler 1982, Demopoulos et al. 1980). Methylprednisolone's antioxidative ability to avert lipid peroxidation can only be exploited if the drug is given in a large dose $(30 \mathrm{mg} / \mathrm{kg}$ i.v.) as soon as possible after the injury (within three hours) with subsequent continual 24-hour application $(5.4 \mathrm{mg} / \mathrm{kg} / \mathrm{h})$. This procedure resulted from three randomised double-blind studies taking place at many centres during the 1979-1998 period under the name of NASCIS (National Acute Spinal Cord Injury Study) I, II, III, and it is regarded as standard method for the treatment of spinal cord injury (Bracken et al. 1984, Bracken et al. 1990, Bracken et al. 1997). As follows from other experiments designed to study the neuroprotective effects of MP in spinal cord trauma, lipid peroxidation is inhibited at a $100 \mu \mathrm{mol}$ MP concentration in the plasma membrane (Anderson et al. 1985). Apart from the primary antioxidative effect, these experiments helped to discover some other neuroprotective effects of MP as well. These include blood circulation control in nervous tissue (Young and Flamm 1982, Hall et al. 1984), aerobic metabolism control (Anderson et al. 1982, Braughler and Hall 1984) and neuronal excitability and synaptic transmission enhancement (Hall 1982).

The spectrum of experimental models designed to test the neuroprotective effects of MP in the brain consists mainly of diffuse brain injury, brain edema and ischemia. In those models, MP is applied intravenously, intraperitoneally or intraarterially in different doses, and the parameters designed to test the effects of MP differ from one another (Hall 1992, Park 1998, Hall and Yonkers 1989, Lin et al. 1994, Shapira et al. 1992, Ildan et al. 1995, Slivka and Murphy 2001). The neuroprotective effect of MP was demonstrated in some experiments (Hall 1985, Park 1998, Ildan et al. 1995) while in others it was not (Shapira et al. 1992). Vasogenic edema reduction in response to MP was documented by Lin et al. (1994). The drug's neuroprotective effect was proved also in some experimental models of brain ischemia (Slivka and Murphy 2001, Braughler and Lainer 1986). The overall dose of MP differs from author to author $(30 \mathrm{mg} / \mathrm{kg}$ up to $105 \mathrm{mg} / \mathrm{kg}$ ) as do the dosage (at least one, at most five doses) and time of infusion (a few minutes up to $12 \mathrm{~h}$ ). This shows lack of uniformity in experimental testing for MP neuroprotective effects on the brain, thus bringing out the fact that its primary effect on brain cells has yet to be fully elucidated.

Experimental evidence of MP neuroprotective effect on spinal cord injury can therefore also be used in experimental brain injury - however, there are significantly fewer, their complete analysis is missing and the results are not unambiguous. It is not yet possible to explain why the neuroprotective effect of MP in one part of the central nervous system - the spinal cord is confirmed, while it is not described in the other part - in the brain. However, experimental models of diffuse brain 
injury and spinal cord injury provide important information on the length of post-traumatic opening of the blood-brain barrier (BBB) and the blood-spinal cord barrier (BSB). While this opening at the BBB takes a few minutes, the BSB is more permeable for several days after the injury (Whetstone et al. 2003, Popovich et al. 1996, Barzó et al. 1993, Marmarou 2007). Because MP does not penetrate intact $\mathrm{BBB}$ nor $\mathrm{BSB}$, it is possible that these time data explain the difference in the neuroprotective effect of MP between the spinal cord and the brain.

In addition to the total amount and dose of MP at certain time intervals, successful use of its neuroprotective properties may be affected by the route of administration. In the above mentioned experiments MP was applied mainly intravenously or intraperitoneally and, in one case, intraarterially by way of the caudal artery. For MP to act on the target structure - brain cell membrane - it would have to cross the BBB, regardless of the actual mode of application. Our four experimental studies testing the neuroprotective effect of MP were based on the above facts. MP was applied very early $30 \mathrm{~s}$ to $2 \mathrm{~h}-$ after the onset of edema at a sufficient dose of $50-100 \mathrm{mg} / \mathrm{kg}$ b.w. The dose of $100 \mathrm{mg} / \mathrm{kg}$ was intended for application to the peritoneum; we used half the dose for the injection into the internal carotid artery. We assumed that the amount of active substance applied to the carotid, i.e. directly to the brain, could be significantly less than the amount needed to deliver the same substance to the systemic vascular bed and that the substance applied to the carotid quickly reached high intracerebral concentrations. Condicio sine qua non was to apply MP during the open BBB. We achieved this by applying MP during or just after the end of WI or after BBBd with mannitol.

When testing the effect of MP, we did not consider it necessary to evaluate the clinical manifestations of the rats - there was never death or visible signs of the motor deficit. Our previous works have shown changes in the behavior of the rats locomotion, rearing and grooming - after induction of the brain edema (Kozler et al. 2013, Kozler et al. 2014, Kozler et al. 2017). All these rat activities after edema induction became inhibited. This was due to the generally suppressive effect of brain edema without any isolated damage in the structures generating individual activities (Sousa et al. 2006). Compared to the apparent evidence of MP effect from neurohistological studies, ICP studies and MRI studies, we see no added value in monitoring clinical changes after MP treatment.

\section{Conclusions}

The neuroprotective effect of methylprednisone (MP) on the permeability of cytoplasmatic membranes of neuronal populations was proved. MP was injected in three different ways: (1) intraperitoneally during the induction of cytotoxic edema or immediately after finishing cytotoxic edema induction in a dose of $100 \mathrm{mg} / \mathrm{kg}$ b.w.; (2) into the internal carotid artery within $2 \mathrm{~h}$ after finishing cytotoxic edema induction in a dose of $50 \mathrm{mg} / \mathrm{kg} \mathrm{b.w.;} \mathrm{(3)} \mathrm{into} \mathrm{internal} \mathrm{carotid} \mathrm{artery} 10 \mathrm{~min}$ after edema induction by BBBd in a dose of $50 \mathrm{mg} / \mathrm{kg}$ b.w. We used purely experimental models of brain edema in rats - water intoxication model and osmotic BBB disruption model - without the occurrence of any pathological condition, which approaches more closely the interpretation of MP effect at the cellular level.

It is hoped that these clear results can be further explored in the form of a clinical trial.

\section{Conflict of Interest}

There is no conflict of interest.

\section{Acknowledgements}

Supported by grant Progress Q35/LF1.

\section{References}

AMAR AP, LEVY ML: Pathogenesis and pharmacological strategies for mitigating secondary damage in acute spinal cord injury. Neurosurgery 44: 1027-1040, 1999. https://doi.org/10.1097/00006123-199905000-00052

ANDERSON DK, MEANS ED, WATERS TR: Microvascular perfusion and metabolism in injured spinal cord after methylprednisolone treatment. J Neurosurg 56: 106-113, 1982. https://doi.org/10.3171/jns.1982.56.1.0106

ANDERSON DK, SAUNDERS RD, DEMEDIUK P: Lipid hydrolysis and peroxidation in injured spinal cord: partial protection with methylprednisolone or vitamin E and selenium. Cent Nerv Syst Trauma 2: 257-267, 1985. https://doi.org/10.1089/cns.1985.2.257 
AYATA C, ROPPER AH: Ischaemic brain oedema. J Clin Neurosci 9: 113-124, 2002. https://doi.org/10.1054/jocn.2001.1031

BARZÓ P, MARMAROU A, FATOUROS P, HAYASAKI K, CORWIN F: Contribution of vasogenic and cellular edema to traumatic brain swelling measured by diffusion-weighted imaging. J Neurosurg 87: 900-907, 1997. https://doi.org/10.3171/jns.1997.87.6.0900

BETZ AL, IANNOTTI F, HOFF JT: Brain edema: a classification based on blood-brain barrier integrity. Cerebrovasc Brain Metab Rev 1: 133-154, 1989.

BRACKEN MB, COLLINS WF, FREEMAN DF, SHEPARD MJ, WAGNER FW, SILTEN RM, HELLENBRAND FG, RANSOHOFF J, HUNT WF, PEROT PL, GROSSMEN RG, GREEN BA, EISENBERG HM, RIFKINSON N, GOODMAN JH, MEAGHER JN, FISHER B, CLIFTON GL, FLAMM ES, RAWE SE: Efficacy of methylprednisolone in acute spinal cord injury. JAMA 251: 45-52, 1984.

BRACKEN MB, SHEPARD MJ, COLLINS WF, HOLFORD TR, YOUNG W, BASKIN D S, EISENBERG HM, FLAMM E, LEO-SUMMERS L, MAROON JC, MARSHALL LF, PEROT PL, PIEPMEIER J, SONNTAG VKH, WAGNER FC, WILBERGER JE, WINN HR: A randomized trial of methylprednisolone or naloxone in the treatment of acute spinal-cord injury: results of the second national acute spinal cord injury study. N Engl J Med 322: 1405-1411, 1990. https://doi.org/10.1056/NEJM199005173222001

BRACKEN MB, SHEPARD MJ, HOLFORD TR, LEO-SUMMERS L, ALDRICH EF, FAZL M, FEHLINGS M, HERR DL, HITCHON PW, MARSHALL LF, NOCKELS RP, PASCALE V, PEROT PL, PIEPMEIER J, SONNTAG VKH, WAGNER F, WILBERGER JE, WINN HR, YOUNG W: Administration of methylprednisolone for 24 or 48 hours or tirilizad mesylate for 48 hours in the treatment of acute spinal cord injury. JAMA 277: 1597-1604, 1997. https://doi.org/10.1097/00132586-199808000-00011

BRAUGHLER JM, HALL ED: Effects of multi-dose methylprednisolone sodium succinate administration on injured cat spinal cord neurofilament degradation and energy metabolism J Neurosurg 61: 290-295, 1984. https://doi.org/10.3171/jns.1984.61.2.0290

BRAUGHLER JM, LAINER MJ: The effects of large doses of methylprednisolone on neurologic recovery and survival in the Mongolian gerbil following three hours of unilateral carotid occlusion. Cent Nerv Syst Trauma 3: 153-162, 1986. https://doi.org/10.1089/cns.1986.3.153

BROMAN T, OLSSON O: Experimental study of contrast media for cerebral angiography with reference to possible injurious effects on the cerebral blood vessels. Acta Radiol 49: 321-334, 1949. https://doi.org/10.3109/00016924909134716

CHI OZ, LEE DI, LIU X, WEISS HR: The effects of morphine on blood-brain barrier disruption caused by intracarotid injection of hyperosmolar mannitol in rats. Anesth Analg 90: 603-608, 2000. https://doi.org/10.1097/00000539200003000-00019

CLASEN RA, HUCKMAN MS, VON ROENN KA, PANDOLFI S, LAING I, LOBICK JJ: A correlative study of computed tomography and histology in human and experimental vasogenic cerebral edema. J Comput Assist Tomogr 5: 313-327, 1981. https://doi.org/10.1097/00004728-198106000-00001

DEMOPOULOS HB, FLAMM ES, PIETRONIGRO DD: The free radical pathology and the microcirculation in the major central nervous system disorders. Acta Physiol Scand 492: 91-119, 1980.

FADEN AI, SALZMAN S: Pharmacological strategies in CNS trauma. Trends Pharmacol Sci 13: 29-35, 1992. https://doi.org/10.1016/0165-6147(92)90013-V

HALL ED: Glucocorticoid effects on central nervous excitability and synaptic transmission. Int Rev Neurobiol 23: 165-195, 1982. https://doi.org/10.1016/S0074-7742(08)60625-X

HALL ED: High-dose glucocorticoid treatment improves neurological recovery in head-injured mice. J Neurosurg 62 : 882-887, 1985. https://doi.org/10.3171/jns.1985.62.6.0882

HALL ED, YONKERS PA: Comparison of two ester prodrugs of methylprednisolone on early neurologic recovery in a murine closed head injury model. J Neurotrauma 6: 163-168, 1989. https://doi.org/10.1089/neu.1989.6.163

HALL ED: The neuroprotective pharmacology of methylprednisolone. J Neurosurg 76: 13-22, 1992. https://doi.org/10.3171/jns.1992.76.1.0013

HALL ED: The role of oxygen radicals in traumatic injury: Clinical implications. J Emerg Med 11: 31-36, 1993. 
HALL ED, BRAUGHLER JM: Effects of intravenous methylprednisolone on spinal cord lipid peroxidation and (Na+ + $\mathrm{K}+$ )-ATPase activity: Dose-response analysis during 1st hour after contusion injury in the cat. J Neurosurg 57 : 247-253, 1982. https://doi.org/10.3171/jns.1982.57.2.0247

HALL ED, WOLF DL, BRAUGHLER JM: Effects of a single large dose of methylprednisolone sodium succinate on experimental posttraumatic spinal cord ischemia. Dose-response and time-action analysis. J Neurosurg 61: 124-130, 1984. https://doi.org/10.3171/jns.1984.61.1.0124

ILDAN F, POLAT S, ONER A, ISBIR T, CETINALP E, KAYA M, KARADAYI A: The effect of the treatment of high-dose methylprednisolone on $\mathrm{Na}+-\mathrm{K}+/ \mathrm{Mg}+2$ ATPase activity and lipid peroxidation and ultrastructural findings following cerebral contusion in rat. Surg Neurol 44: 573-580, 1995. https://doi.org/10.1016/00903019(95)00219-7

JHA RM, KOCHANEK PM, SIMARD JM: Pathophysiology and treatment of cerebral edema in traumatic brain injury. Neuropharmacology 145: 230-246, 2019. https://doi.org/10.1016/j.neuropharm.2018.08.004

KAYA M, GULTURK S, ELMAS I, KALAYCI R, ARICAN N, KOCYILDIZ ZC, KUCUK M, YORULMAZ H, SIVAS A: The effects of magnesium sulfate on blood-brain barrier disruption caused by intracarotid injection of hyperosmolar mannitol in rats. Life Sci 26: 201-212, 2004. https://doi.org/10.1016/j.1fs.2004.07.012

KEMPSKI O: Cerebral edema. Semin Nephrol 21: 303-307, 2001. https://doi.org/10.1053/snep.2001.21665

KIMELBERG HK: Current concepts of brain edema. Review of laboratory investigations. J Neurosurg 83: 1051-1059, 1995. https://doi.org/10.3171/jns.1995.83.6.1051

KLATZO I: Presidential address. Neuropathological aspects of brain edema. J Neuropathol Exp Physiol 26: 1-14, 1967. https://doi.org/10.1097/00005072-196701000-00001

KOCHANEK PM, JACKSON TC, FERGUSON NM, CARLSON SW, SIMON DW, BROCKMAN EC, JI J, BAYIR H, POLOYAC SM, WAGNER AK, KLINE AE, EMPEY PE, CLARK RSB, JACKSON EK, DIXON CE: Emerging therapies in traumatic brain injury. Semin Neurol 35: 83-100, 2015. https://doi.org/10.1055/s-0035-1544237

KOZLER P, POKORNÝ J: Altered blood-brain barrier permeability and its effect on the distribution of Evans blue and sodium fluorescein in the rat brain applied by intracarotid injection. Physiol Res 52: 607-614, 2003.

KOZLER P, POKORNÝ J: Effects of intracarotid injection of methylprednisolone on cellular oedema after osmotic opening of the blood-brain barrier in rats. Prague Med Rep 105: 279-290, 2004.

KOZLER P, RILJAK V, POKORNÝ J: Time-dependent axonal impairment in experimental model of brain oedema. Neuro Endocrinol Lett 31: 477-482, 2010.

KOZLER P, POKORNY J: Effect of methylprednisolone on the axonal impairment accompanying cellular brain oedema induced by water intoxication in rats. Neuro Endocrinol Lett 33: 782-786, 2012.

KOZLER P, RILJAK V, POKORNÝ J: Both water intoxication and osmotic BBB disruption increase brain water content in rats. Physiol Res 62 (Suppl 1): S75-S80, 2013. https://doi.org/10.33549/physiolres.932566

KOZLER P, POKORNÝ J: CT density decrease in water intoxication rat model of brain oedema. Neuro Endocrinol Lett 35: 608-612, 2014.

KOZLER P, RILJAK V, JANDOVÁ K, POKORNÝ J: CT imaging and spontaneous behavior analysis after osmotic blood-brain barrier opening in Wistar rat. Physiol Res 63 (Suppl 4): S529-S534, 2014. https://doi.org/10.33549/physiolres.932935

KOZLER P, SOBEK O, POKORNÝ J: Signs of myelin impairment in cerebrospinal fluid after osmotic opening of the blood-brain barrier in rats. Physiol Res 64 (Suppl 5): S603-S608, 2015. https://doi.org/10.33549/physiolres.933220

KOZLER P, MAREŠOVÁ D, POKORNÝ J: Methylprednisolone modulates intracranial pressure in the brain cellular edema induced by water intoxication. Physiol Res 66 (Suppl 4): S511-S516, 2017. https://doi.org/10.33549/physiolres.933797

KOZLER P, MAREŠOVA D, POKORNÝ J: Study of locomotion, rearing and grooming activity after single and/or concomitant lesions of central and peripheral nervous system in rats. Neuro Endocrinol Lett 38: 495-501, 2017.

KOZLER P, MAREŠOVA D, POKORNÝ J: Cellular brain edema induced by water intoxication in rat experimental model. Neuro Endocrinol Lett 39: 209-218, 2018.

KOZLER P, HERYNEK V, MAREŠOVÁ D, PEREZ PD, ŠEFC L, POKORNÝ J: Effect of methylprednisolone on experimental brain edema in magnetic resonance imaging. Physiol Res 16: 919-926, 2020. https://doi.org/10.33549/physiolres.934460 
KROLL RA, NEUWELT EA: Outwitting the blood-brain barrier for therapeutic purposes: osmotic opening and other means. Neurosurgery 42: 1083-1100, 1998. https://doi.org/10.1097/00006123-199805000-00082

KUCINSKI T, VÄTERLEIN O, GLAUCHE V, FIEHLER J, KLOTZ E, ECKERT B, KOCH C, RÖTHER J, ZEUMER H: Correlation of apparent diffusion coefficient and computed tomography density in acute ischemic stroke. Stroke 33: 1786-1791, 2002. https://doi.org/10.1161/01.STR.0000019125.80118.99

LOUBINOUX I, VOLK A, BORREDON J, GUIRIMAND S, TIFFON B, SEYLAZ J, MÉRIC P: Spreading of vasogenic edema and cytotoxic edema assessed by quantitative diffusion and $\mathrm{T} 2$ magnetic resonance imaging. Stroke 28: 419-426, 1997. https://doi.org/10.1161/01.STR.28.2.419

LAFUENTE JV, POUSCHMAN E, CERVÓS-NAVARRO J, SHARMA HS, SCHREINER C, KORVES M: Dynamics of tracer distribution in radiation induced brain oedema in rats. Acta Neurochir 51 (Suppl): 375-377, 1990. https://doi.org/10.1007/978-3-7091-9115-6_126

LIANG D, BHATTA S, GERZANICH V, SIMARD JM: Cytotoxic edema: mechanisms of pathological cell swelling. Neurosurg Focus 22: E2, 2007. https://doi.org/10.3171/foc.2007.22.5.3

LIN SZ, CHIOU TL, CHIANG YH, SONG WS: Combined treatment with nicardipine, phenobarbital, and methylprednisolone ameliorates vasogenic brain edema. Acta Neurochir 60: 528-530, 1994. https://doi.org/10.1007/978-3-7091-9334-1_145

LYTHGOE MF, THOMAS DL, CALAMANTE F, PELL GS, KING MD, BUSZA AL, SOTAK CH, WILLIAMS SR, ORDIDGE RJ, GADIAN DG: Acute changes in MRI diffusion, perfusion T(1), and T(2) in a rat model of oligemia produced by partial occlusion of the middle cerebral artery. Magn Reson Med 44: 706-712, 2000. https://doi.org/10.1002/1522-2594(200011)44:5<706::AID-MRM8>3.0.CO;2-1

MANGEL L, VÖNÖCZKY K, HANZÉLY Z, KISS T, AGOSTON P, SOMOGYI A, NÉMETH G: CT densitometry of the brain: A novel method for early detection and assessment of irradiation induced brain edema. Neoplasma 49: 237-242, 2002.

MANLEY GT, FUJIMURA M, MA T, NOSHITA N, FILIZ F, BOLLEN AW, CHAN P, VERKMAN AS: Aquaporin-4 deletion in mice reduces brain edema after acute water intoxication and ischemic stroke. Nat Med 6: 159-163, 2000. https://doi.org/10.1038/72256

MARCHI N, BETTO G, FAZIO V, FAN Q, GHOSH C, MACHADO A, JANIGRO D: Blood-brain barrier damage and brain penetration of antiepileptic drugs: role of serum proteins and brain edema. Epilepsia 50: 664-677, 2009. https://doi.org/10.1111/j.1528-1167.2008.01989.x

MARMAROU A: Pathophysiology of traumatic brain edema: current concepts. Acta Neurochir (Suppl) 86: 7-10, 2003. https://doi.org/10.1007/978-3-7091-0651-8_2

MARMAROU A: A review of progress in understanding the pathophysiology and treatment of brain edema. Neurosurg Focus 15: E1, 2007. https://doi.org/10.3171/foc.2007.22.5.2

MICHINAGA S, KOYAMA Y: Pathogenesis of brain edema and investigation into anti-edema drugs. Int J Mol Sci 16: 9949-9975, 2015. https://doi.org/10.3390/ijms16059949

ONAYA M: Neuropathological investigation of cerebral white matter lesions caused by closed head injury. Neuropathology 22: 243-251, 2002. https://doi.org/10.1046/j.1440-1789.2002.00456.x

PARK CO: The effects of methylprednisolone on prevention of brain edema after experimental moderate diffuse brain injury in rats: comparison between dosage, injection time, and treatment methods. Yonsei Med J 39: 395-403, 1998. https://doi.org/10.3349/ymj.1998.39.5.395

POPOVICH PG, HORNER PJ, MULLIN BB, STOKES BT: A quantitative spatial analysis of the blood-spinal cord barrier. I. Permeability changes after experimental spinal contusion injury. Exp Neurol 142: 258-275, 1996. https://doi.org/10.1006/exnr.1996.0196

RAPOPORT SI, FREDERICKS WR, OHNO K, PETTIGREW KD: Quantitative aspects of reversible osmotic disruption of the blood-brain barrier. Am J Physiol 238: R421-R431, 1980. https://doi.org/10.1152/ajpregu.1980.238.5.R421

RAPOPORT SI: Osmotic opening of the blood-brain barrier: Principles, mechanism, and therapeutic applications. Cell Mol Neurobiol 20: 217-230, 2000. https://doi.org/10.1023/a:1007049806660

SARIS SC, WRIGHT DC, OLDFIELD EH, BLASBERG RC: Intravascular streaming and variable delivery to brain following carotid artery infusions in the Sprague-Dawley rat. J Cereb Blood Flow Metab 8: 116-120, 1988. https://doi.org/10.1038/jcbfm.1988.15 
SHAPIRA Y, ARTRU AA, YADID G, SHOHAMI E: Methylprednisolone does not decrease eicosanoid concentrations or edema in brain tissue or improve neurologic outcome after head trauma in rats. Anesth Analg 75: 238-244, 1992. https://doi.org/10.1213/00000539-199208000-00015

SILVER SM, SCHROEDER BM, BERNSTEIN P, STERNS RH: Brain adaptation to acute hyponatremia in young rats. Am J Physiol 276: R1595-R1599, 1999. https://doi.org/10.1152/ajpregu.1999.276.6.R1595

SLIVKA PA, MURPHY EJ: High-dose methylprednisolone treatment in experimental focal cerebral ischemia. Exp Neurol 167: 166-172, 2001. https://doi.org/10.1006/exnr.2000.7532

SORBY-ADAMS AJ, MARCOIONNI AM, DEMPSEY ER, WOENIG JA, TURNER RJ: The role of neurogenic inflammation in blood-brain barrier disruption and development of cerebral oedema following acute central nervous system (CNS) injury. Int J Mol Sci 18: E1788, 2017. https://doi.org/10.3390/ijms18081788

SOUSA N, ALMEIDA OF, WOTJAK CT: A hitchhiker's guide to behavioral analysis in laboratory rodents. Genes Brain Behav (Suppl 2): 5-24, 2006. https://doi.org/10.1111/j.1601-183X.2006.00228.X

STOKUM JA, GERZANICH V, SIMARD JM: Molecular pathophysiology of cerebral edema. J Cereb Blood Flow Metab 36: 513-538, 2016. https://doi.org/10.1177/0271678X15617172

STOKUM JA, GERZANICH V, SHETH KN, KIMBERLY WT, SIMARD JM: Emerging pharmacological treatments for cerebral edema: Evidence from clinical studies. Annu Rev Pharmacol Toxicol 60: 291-309, 2020. https://doi.org/10.1146/annurev-pharmtox-010919-023429

TORACK RM: Computed tomography and stroke edema: case report with an analysis of water in acute infarction. Comput Radiol 6: 35-41, 1982. https://doi.org/10.1016/0730-4862(82)90179-2

VENERO JL, VIZUETE ML, MACHADO A, CANO J: Aquaporins in the central nervous system. Prog Neurobiol 63: 321-336, 2001. https://doi.org/10.1016/S0301-0082(00)00035-6

WHETSTONE WD, HSU JY, EISENBERG M, WERB Z, NOBLE-HAEUSSLEIN LJ: Blood-spinal cord barrier after spinal cord injury: relation to revascularization and wound healing. J Neurosci Res 74: 227-239, 2003. https://doi.org/10.1002/jnr.10759

WOLMAN M, KLATZO I, CHUI E, WILMES F, NISHIMOTO K, FUJIWARA K, SPATZ M: Evaluation of the dyeprotein tracers in pathophysiology of the blood-brain barrier. Acta Neuropathol 54: 55-61, 1981. https://doi.org/10.1007/BF00691332

www.rxmed.com/b.main/b2.pharmaceutical/OCTOSTIM.html

www.pfizer.cz/sites/pfizer.cz/files/g10034396/f/201608/Solu-Medrol_40mg_PIL.pdf.

YANG B, ZADOR Z, VERKMAN AS: Glial cell aquaporin-4 overexpression in transgenic mice accelerates cytotoxic brain swelling. J Biol Chem 22: 15280-15286, 2008. https://doi.org/10.1074/jbc.M801425200

YOUNG W, FLAMM ES: Effect of high-dose corticosteroid therapy on blood flow, evoked potentials, and extracellular calcium in experimental spinal injury. J Neurosurg 57: 667-673, 1982. https://doi.org/10.3171/jns.1982.57.5.0667 